ISSN 2075-4701

www.mdpi.com/journal/metals/

Article

\title{
Fatigue Behavior of an Ultrafine-Grained Al-Mg-Si Alloy Processed by High-Pressure Torsion
}

\author{
Maxim Murashkin ${ }^{1,2}, *$, Ilchat Sabirov ${ }^{3}$, Dmitriy Prosvirnin ${ }^{4, \dagger}$, Ilya Ovid'ko ${ }^{5}$, \\ Vladimir Terentiev ${ }^{4, \dagger}$, Ruslan Valiev ${ }^{1,2}$ and Sergey Dobatkin ${ }^{4, \dagger}$
}

1 Institute for Physics of Advanced Materials, Ufa State Aviation Technical University, Ufa 450000, Russia; E-Mail: rzvaliev@ mail.rb.ru

2 Laboratory for Mechanics of Bulk Nanostructured Materials, Saint Petersburg State University, Saint-Petersburg 199034 Russia

3 IMDEA Materials Institute, Getafe, Madrid 28906, Spain; E-Mail: ilchat.sabirov@imdea.org

4 Baikov Institute for Metallurgy and Materials Science of the Russian Academy of Sciences, Moscow 119991, Russia; E-Mails: imetran@yandex.ru (D.P.); fatig@mail.ru (V.T.); dobatkin@ultra.imet.ac.ru (S.D.)

5 Research Laboratory for Mechanics of New Nanomaterials, Saint-Petersburg State Polytechnical University, Saint-Petersburg 195251, Russia; E-Mail: ovidko@gmail.com

$\dagger$ These authors contributed equally to this work.

* Author to whom correspondence should be addressed; E-Mail: m.murashkin.70@gmail.com; Tel.: +7-3472-734449; Fax: +7-3472-733422.

Academic Editor: Heinz Werner Höppel

Received: 24 March 2015 / Accepted: 31 March 2015 / Published: 10 April 2015

\begin{abstract}
The paper presents the evaluation of the mechanical and fatigue properties of an ultrafine-grained (UFG) Al 6061 alloy processed by high-pressure torsion (HPT) at room temperature (RT). A comparison is made between the UFG state and the coarse-grained (CG) one subjected to the conventional aging treatment T6. It is shown that HPT processing leads to the formation of the UFG microstructure with an average grain size of $170 \mathrm{~nm}$. It is found that yield strength $\left(\sigma_{0.2}\right)$, ultimate tensile strength $\left(\sigma_{\text {UTS }}\right)$ and the endurance limit $\left(\sigma_{\mathrm{f}}\right)$ in the UFG Al 6061 alloy are higher by a factor of 2.2, 1.8 and 2.0 compared to the CG counterpart subjected to the conventional aging treatment T6. Fatigue fracture surfaces are analyzed, and the fatigue behavior of the material in the high cycle and low cycle regimes is discussed.
\end{abstract}


Keywords: Al alloy; severe plastic deformation; high pressure torsion; ultrafine-grained microstructure; mechanical strength; fatigue properties

\section{Introduction}

The enhancement in the level of physical and mechanical properties in Al alloys as a result of ultrafine-grained (UFG) structure formation induced by severe plastic deformation (SPD) is currently of great interest [1-5]. As a rule, SPD processing leads to the formation of the microstructure with a grain/subgrain size in the range of $50 \mathrm{~nm}-1 \mu \mathrm{m}$ in bulk Al billets [1-5]. Earlier, it was demonstrated that UFG Al alloys have a mechanical strength 1.2-2.0-times as much as their coarse-grained (CG) counterparts processed by a standard aging treatment $[1-4,6]$. Numerous studies have also shown that other properties, including ductility [1,7,8], fracture resistance [9] and electrical conductivity [1,10,11], can be enhanced. The fatigue behavior of the UFG Al alloys has been widely studied over the last decade, and a detailed overview of those studies can be found in [12-17]. The outcomes of these studies can be roughly generalized as follows. The high-cycle fatigue (HCF) properties are usually not enhanced as significantly as mechanical strength. An insignificant improvement in fatigue life observed in the UFG Al alloys in the HCF regime was related to a low increase in resistance against crack nucleation, as the fatigue life in the HCF is determined by the resistance of material to the crack nucleation [13]. The low cycle fatigue (LCF) behavior of the UFG Al alloys is very complex, since ultrafine grains have a low ability to sustain cyclic loads in the LCF regime. This was related to the limited ductility on monotonic and cycling deformation promoting early crack initiation, as well as a higher fraction of grain boundaries favorable for crack propagation [13]. Unlike CG Al alloys, their UFG counterparts often show an insignificant increase of the stress amplitude (low cyclic hardening) or even its decrease (cyclic softening) when they are cyclically deformed under a constant strain amplitude [18-20]. Nevertheless, intelligent microstructural design in the UFG Al alloys can significantly improve their HCF and LCF behavior [21,22].

It should be noted that the fatigue behavior of the UFG Al alloys has been studied mainly on specimens processed by equal-channel angular pressing (ECAP) [12-14] or by cryorolling [18,23]. It is well known that the ECAP technique or other ECAP-based methods result in the formation of a UFG microstructure with a grain/subgrain size of 300-500 nm [12-14], whereas a microstructure consisting mainly of cells/subgrains having a similar size is formed during cryorolling [18,23]. However, in the literature, there are no reports on the fatigue properties of the UFG Al alloys with a grain size of $<200 \mathrm{~nm}$, which can demonstrate record mechanical strength up to $1,000 \mathrm{MPa}$ and are usually processed by HPT [24,25]. The main limitation for fatigue studies on the HPT-processed metallic materials was the small size of the processed disks. Recent progress in up-scaling of the HPT technique along with miniaturization of the specimens for fatigue testing allows one to investigate the fatigue properties of the HPT processed disks [26]. Therefore, the main objective of the present work is to study the fatigue properties and fatigue behavior of an HPT-processed Al-Mg-Si alloy with a grain size of $170 \mathrm{~nm}$. The Al-Mg-Si alloy was selected due to the wide application of the material in construction, auto- and aero-space engineering [21] and as a conductor in electrical engineering [27]. 


\section{Experimental Section}

Commercial-grade Al 6061 alloy having a chemical composition (in wt\%) $1.00 \mathrm{Mg}, 0.61 \mathrm{Si}$, $0.12 \mathrm{Cu}, 0.38 \mathrm{Cr}, 0.60 \mathrm{Fe}, 0.02 \mathrm{Ti}$ and balance $\mathrm{Al}$ was selected for this investigation. Disks having a diameter of $20 \mathrm{~mm}$ and a thickness of $1.4 \mathrm{~mm}$ were machined from the as-received hot-pressed rod. The disks were solution-treated at $530{ }^{\circ} \mathrm{C}$ for $2 \mathrm{~h}$ and water quenched. Some disks after water quenching were subjected to the conventional treatment T6, namely artificial ageing at $160{ }^{\circ} \mathrm{C}$ for $12 \mathrm{~h}$.

The disks were HPT processed for 10 rotations at RT under a load of 188 tons (e.g., a pressure of $6 \mathrm{GPa}$ ). The as-processed disks had a thickness of $0.9 \mathrm{~mm}$. The microstructure and properties of the HPT-processed alloy were studied in the areas located at a distance of $\sim 5 \mathrm{~mm}$ (half of radius) from the center of the disks.

Microstructure studies were performed using the transmission electron microscope (TEM, JEOL, Tokyo, Japan) JEM 2100 at an accelerating voltage of $200 \mathrm{kV}$. Observations were made in both the bright and the dark field imaging modes, and selected area electron diffraction (SAED) patterns were recorded from areas of interest using an aperture of a $1-\mu \mathrm{m}$ nominal diameter. The lineal intercept method was used to estimate the grain size. At least 200 grains were analyzed to estimate the average grain size.

Specimens for tensile testing and fatigue testing were machined from the solution-treated material and HPT-processed disks. The central axis of the tensile and fatigue specimens was located at a distance of $5.2 \mathrm{~mm}$ from the disk center, as shown in Figure 1, where a drawing of the samples is also presented. Two specimens were machined from each disk. All machined tensile and fatigue specimens were mechanically polished to a mirror-like surface using silica colloidal solution at the final stage. Tensile tests were carried out using an Instron 8862 universal testing machine (JEOL, Tokyo, Japan). Tensile specimens were deformed to failure at room temperature with a constant cross-head speed corresponding to an initial strain rate of $10^{-3} \mathrm{~s}^{-1}$. Three tensile specimens were tested for each material condition, and the results thus obtained were found to be reproducible.

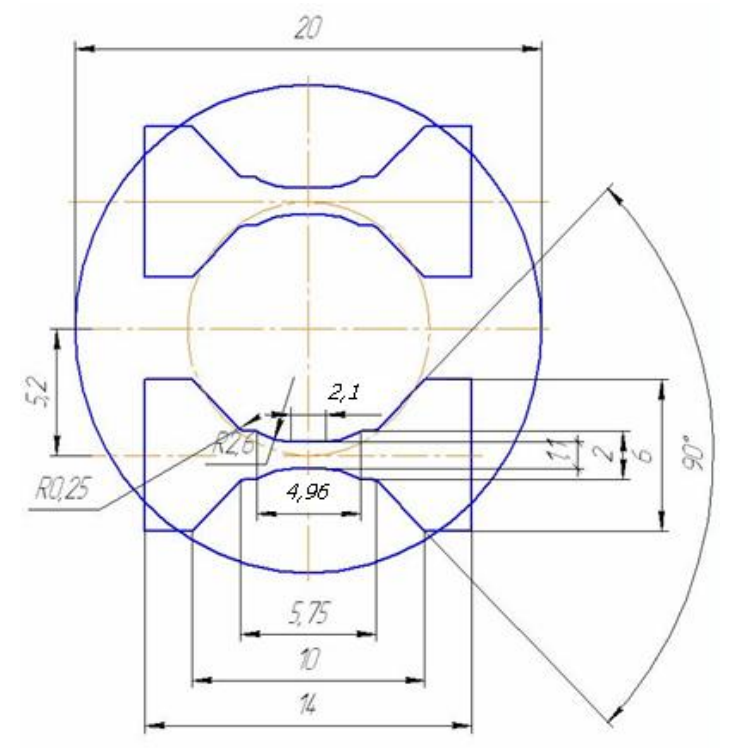

Figure 1. Schematic drawing of specimens machined from disks. 
Fatigue testing was carried out using an Instron Electropuls E 3000 testing module with a frequency of $30 \mathrm{~Hz}$ under repeated tension conditions with a constant minimum cycle stress of $\sigma_{\min }=100 \mathrm{MPa}$.

The fatigue fracture surfaces were studied using the scanning electron microscope (SEM, JEOL, Tokyo, Japan) JSM-6490LV operating at an accelerating voltage of $20 \mathrm{kV}$. The SEM is equipped with the INCA X-sight attachment for energy-dispersive X-ray (EDX) analysis.

\section{Results and Discussion}

\subsection{Effect of HPT Processing on Microstructure of the Al 6061 Alloy}

Figure 2 illustrates the microstructure of the Al 6061 alloy before and after HPT processing. Conventional treatment $\mathrm{T} 6$ of the as-received alloy resulted in the formation of a CG microstructure with an average grain size of $70 \mu \mathrm{m}$ (Figure 2a). Particles of primary excess phase forming bands oriented along the pressing direction are observed in the microstructure (Figure 2a). They have a complex chemical composition of $\mathrm{Al}_{68} \mathrm{Fe}_{21} \mathrm{Si}_{6.5} \mathrm{Cr}_{2.5}$ (wt $\%$ ) and are typically formed during the crystallization of slabs. These particles have a spherical shape; their average size is about $1.8 \mu \mathrm{m}$, and the volume fraction is about $2.4 \%$. Such a distribution of these particles is usually observed in the hot-pressed Al-Mg-Si alloys. Second phase precipitates having a needle shape are also present in the microstructure (Figure 2b). As is well known, these are the metastable $\beta$ "- $\mathrm{Mg}_{2} \mathrm{Si}$ precipitates, which are typically formed during T6 treatment of the Al-Mg-Si alloys [28,29].

HPT processing of the solution-treated Al 6061 alloy resulted in the formation of a very homogeneous UFG microstructure consisting mainly of equiaxed grains having an average size of $170 \mathrm{~nm}$ (Figure 2c,d). This is also confirmed by SAED patterns (Figure 2d). No precipitates, like Guinier-Preston zones and/or second phases, were observed in the processed disks. Such a microstructure is typically formed during HPT processing of the Al-Mg-Si alloys [11,30,31]. It should be also noted that earlier studies using the atom probe tomography (APT) technique revealed segregations of $\mathrm{Mg}, \mathrm{Cu}$ and $\mathrm{Si}$ atoms along grain boundaries in the $\mathrm{Al} 6061$ alloy [30] and in the $\mathrm{Al}$ 6060 alloy [32] processed by HPT under similar conditions. HPT processing did not have any effect on the size and volume fraction of the primary excess phases. However, particles changed their orientation and formed a banded structure along the shear plane during HPT processing (Figure 3). It should be noted that in order to avoid the effect of the orientation of the particle bands on the properties of the alloy, specimens for tensile and fatigue testing were cut out, so that particle bands in the gauge sections were oriented along the specimen axis.

\subsection{Effect of HPT Processing on Tensile and Fatigue Behavior of the Al 6061 Alloy}

The results of mechanical tensile testing of the Al 6061 alloy after conventional T6 treatment and HPT processing are presented in Table 1. It is seen that HPT processing resulted in dramatic improvement of the mechanical strength of the material. The yield strength increased from $276 \mathrm{MPa}$ to $605 \mathrm{MPa}$, whereas the ultimate tensile strength increased from $365 \mathrm{MPa}$ to $675 \mathrm{MPa}$. No other SPD processing technique, such as ECAP [33,34], or ECAP combined with cold rolling (CR), or artificial aging (AA) [33], led to such a high mechanical strength in this alloy. Such a significant increase in mechanical strength of the HPT-processed Al 6061 alloy can be related primarily to the formation of a 
homogeneous UFG structure with a very small grain size, promoting the grain size hardening according to the Hall-Petch relationship [2]. At the same time, segregations of solute atoms in the Al solid solution, which were found earlier in the structure of the HPT-processed Al 6061 alloy in [30], can also provide some additional strengthening.

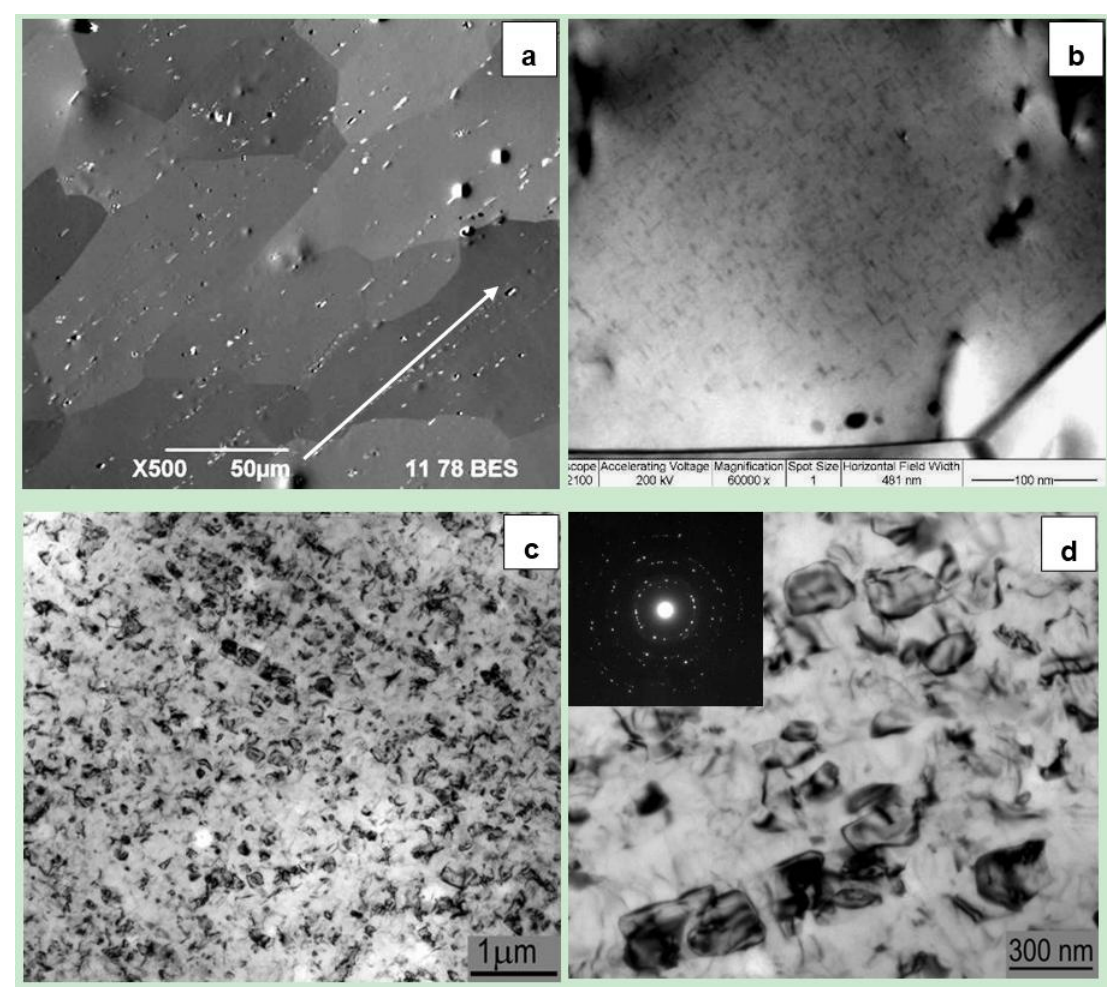

Figure 2. Microstructure of the Al 6061 alloy after conventional T6 treatment (a,b) and high-pressure torsion (HPT) processing at RT (c,d). The arrow indicates the pressing direction and the orientation of the bands formed by primary phase particles.

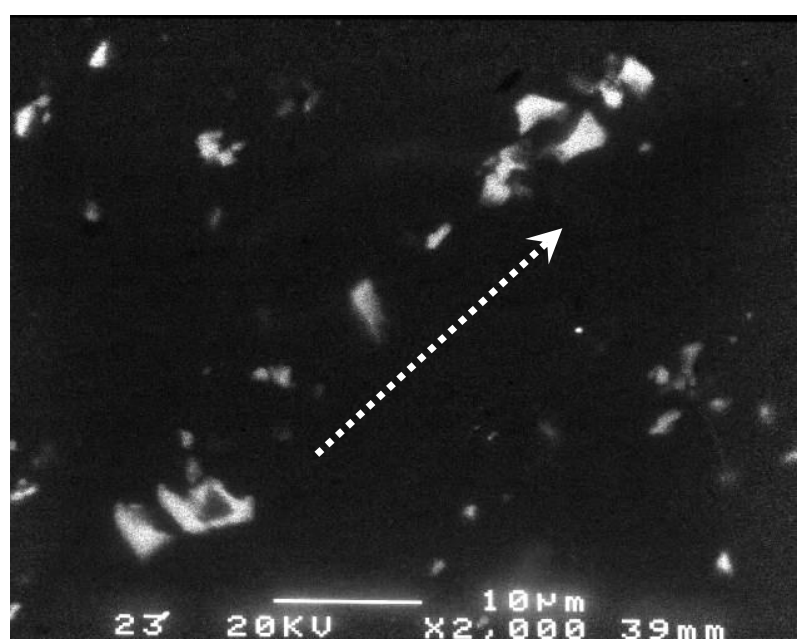

Figure 3. Distribution of the primary excess phases in the Al 6061 alloy processed by HPT at RT (the arrow indicates the shear plane and the orientation of the bands formed by primary phase particles). 
Table 1. Mechanical properties of the Al 6061 alloy in the present work in comparison with the mechanical properties reported in earlier studies. ECAP, equal-channel angular pressing; AA, artificial aging; CR, cold rolling; UFG, ultrafine grained; CG, coarse grained.

\begin{tabular}{|c|c|c|c|c|c|c|c|}
\hline Processing & State & $\sigma_{0.2}(\mathrm{MPa})$ & $\sigma_{\mathrm{UTS}}(\mathrm{MPa})$ & $\delta(\%)$ & $\sigma_{\mathrm{f}}(\mathrm{MPa})$ & $\sigma_{\mathrm{f}} / \sigma_{\mathrm{UTS}}$ & Reference \\
\hline T6 & $\mathrm{CG}$ & 276 & 365 & 14 & 100 & 0.27 & \multirow{2}{*}{ present work } \\
\hline HPT for 10 turns at RT & UFG & 605 & 675 & 5.5 & 200 & 0.30 & \\
\hline T6 & $\mathrm{CG}$ & 275 & 310 & 12 & 97 & 0.31 & {$[34]$} \\
\hline ECAP at $125^{\circ} \mathrm{C}$ for 1 pass & UFG & 310 & 375 & 20 & 80 & 0.21 & {$[21]$} \\
\hline ECAP at $100^{\circ} \mathrm{C}, 4$ passes & UFG & 386 & 434 & 11 & - & - & \multirow{3}{*}[33]{} \\
\hline $\mathrm{ECAP}+\mathrm{AA}\left(130{ }^{\circ} \mathrm{C}\right.$ for $\left.24 \mathrm{~h}\right)$ & UFG & 434 & 470 & 10 & - & - & \\
\hline $\mathrm{ECAP}+\mathrm{CR}(15 \%)$ & UFG & 470 & 500 & 8 & - & - & \\
\hline
\end{tabular}

Figure 4 shows the results of fatigue testing of CG T6 treated and HPT-processed material. It is seen that HPT processing has doubled the endurance limit $\left(\sigma_{\mathrm{f}}\right)$ of the material at $10^{7}$ cycles: it increased from $100 \mathrm{MPa}$ in the T6-treated CG alloy to $200 \mathrm{MPa}$ after HPT processing (Figure 4). It should be noted that the $\sigma_{\mathrm{f}}$-values obtained after cyclic testing of sub-size specimens with the CG microstructure subjected to the conventional T6 treatment are in very good agreement with the results of the testing of standard reference specimens machined from a similar material [12-14,35]. For example, according to the results of fatigue testing of standard samples, the $\sigma_{\mathrm{f}}$-value of the $\mathrm{Al} 6061$ alloy in the T6 state is $97 \mathrm{MPa}[13]$.

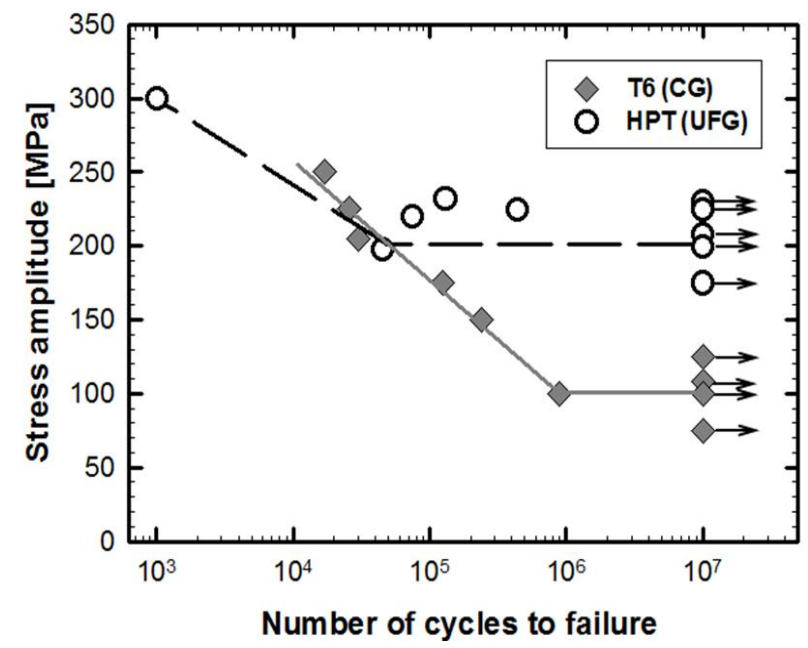

Figure 4. Fatigue curves for the studied Al 6061 alloy.

It should be also noted that the level of $\sigma_{\mathrm{f}}$-value achieved in the HPT-processed Al 6061 alloy with an average grain size of $170 \mathrm{~nm}$ is also twice the cyclic strength of the UFG material with an average grain size of $\sim 500 \mathrm{~nm}$ processed by ECAP in [34].

In Figure 5, the endurance limit is plotted vs. the ultimate tensile strength of the CG Al 6061 alloy processed by conventional thermal treatments $(\mathrm{O}, \mathrm{T} 4, \mathrm{~T} 6)$ and by thermo-mechanical treatment (T91) $[13,35]$. The analysis of the data shows that the ratio of the fatigue limit to the ultimate tensile strength $\left(\sigma_{\mathrm{f}} / \sigma_{\mathrm{UTS}}\right)$ for the given material decreases from $\sim 0.50$ to 0.25 with increasing $\sigma_{\mathrm{UTS}}$ (Figure 5). 
It should be noted that a lower $\sigma_{\mathrm{f}} / \sigma_{\mathrm{UTS}}$ ratio of 0.20 was reported for the UFG Al 6061 alloy processed by ECAP in [21]. Such low $\sigma_{\mathrm{f}} / \sigma_{\mathrm{UTS}}$ ratios were found also in other UFG Al-Mg-Si alloys [12-14]. In our work, grain refinement down to $170 \mathrm{~nm}$ in the Al 6061 alloy via HPT processing resulted in an increase of the $\sigma_{f} / \sigma_{\text {UTS }}$ ratio from 0.27 to 0.30 and in a record value of $\sigma_{f}=200 \mathrm{MPa}$. As is well known, fatigue life in the $\mathrm{HCF}$ regime is determined by the resistance of the material to crack initiation [13]. Unlike UFG Al 6061 alloy produced by ECAP in [34], our UFG alloy shows a very homogeneous grain structure and, therefore, should have also a homogeneous resistance to crack nucleation all over the gauge section without any 'weakest link'. Thus, it can be concluded that further grain refinement down to the nanoscale and the generation of a very homogeneous grain structure can be proposed as a recipe for the improvement of HCF properties in the Al alloys.

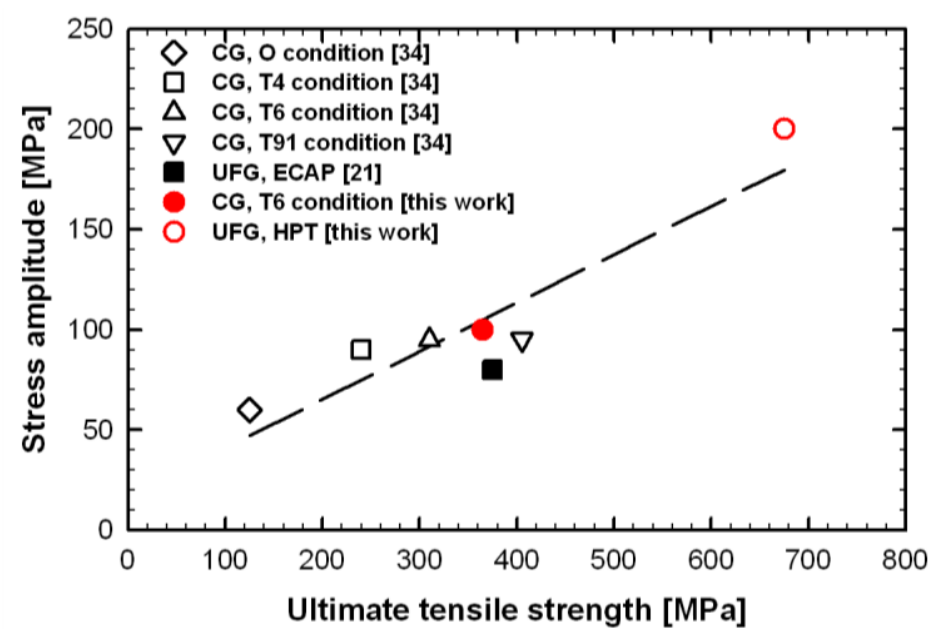

Figure 5. Ultimate tensile strength vs. endurance limit for the Al 6061 alloy subjected to various processing treatments.

In the LCF regime, the endurance limit of the HPT-processed Al alloy was somewhat lower than in its CG counterpart (Figure 4). This observation can be rationalized based on the low strain hardening ability of the UFG material, compared to that of the CG T6 one (Table 1), promoting early crack initiation, as well as a much higher volume fraction of grain boundaries favorable for crack propagation [13].

\subsection{Analysis of Fatigue Fracture Surfaces}

Figures 6 and 7 present SEM images of the fatigue fracture surface of CG T6-treated and HPT-processed Al 6061 alloy, respectively. The area of fatigue crack initiation in the CG T6 material is located on the surface of specimens and is extended into the specimen by $\sim 150 \mu \mathrm{m}$ (Figure $6 \mathrm{a}$ ). This is known as Stage I or the short crack growth propagation stage. The increase of the stress intensity factor $K$ as a consequence of crack growth results in the development of slips in different planes close to the crack tip, initiating Stage II, e.g., the stage of stable fatigue crack growth (Figure 6b). An important characteristic of Stage II is the presence of surface ripples, known as "striations". The ductile striations are clearly observed on the fatigue fracture surface (Figure 6c). Their width is in the range of $1-2 \mu \mathrm{m}$. The average width of striations is about $3 \mu \mathrm{m}$. The most accepted mechanism for the formation of striations is the successive blunting and re-sharpening of the crack tip during cyclic 
loading [35,36]. Striations are grouped in areas of homogenous propagation separated by tear ridges in which the material fails by shearing, resulting in the apparent continuity of the fatigue advancing front. Finally, Stage III is related to unstable crack growth as $K$ approaches $K_{I C}$ (Figure 6e). At this stage, crack growth is controlled by static modes of failure and is very sensitive to the microstructure, load ratio and stress state. The ductile fracture surface consisting of spherical dimples is observed (Figure $6 \mathrm{~g}$ ). The size of the dimples is in the range of 2-20 $\mu \mathrm{m}$. Figure $6 \mathrm{~g}$ shows a fracture pattern within the transition area from a fatigue fracture to the final breakdown.
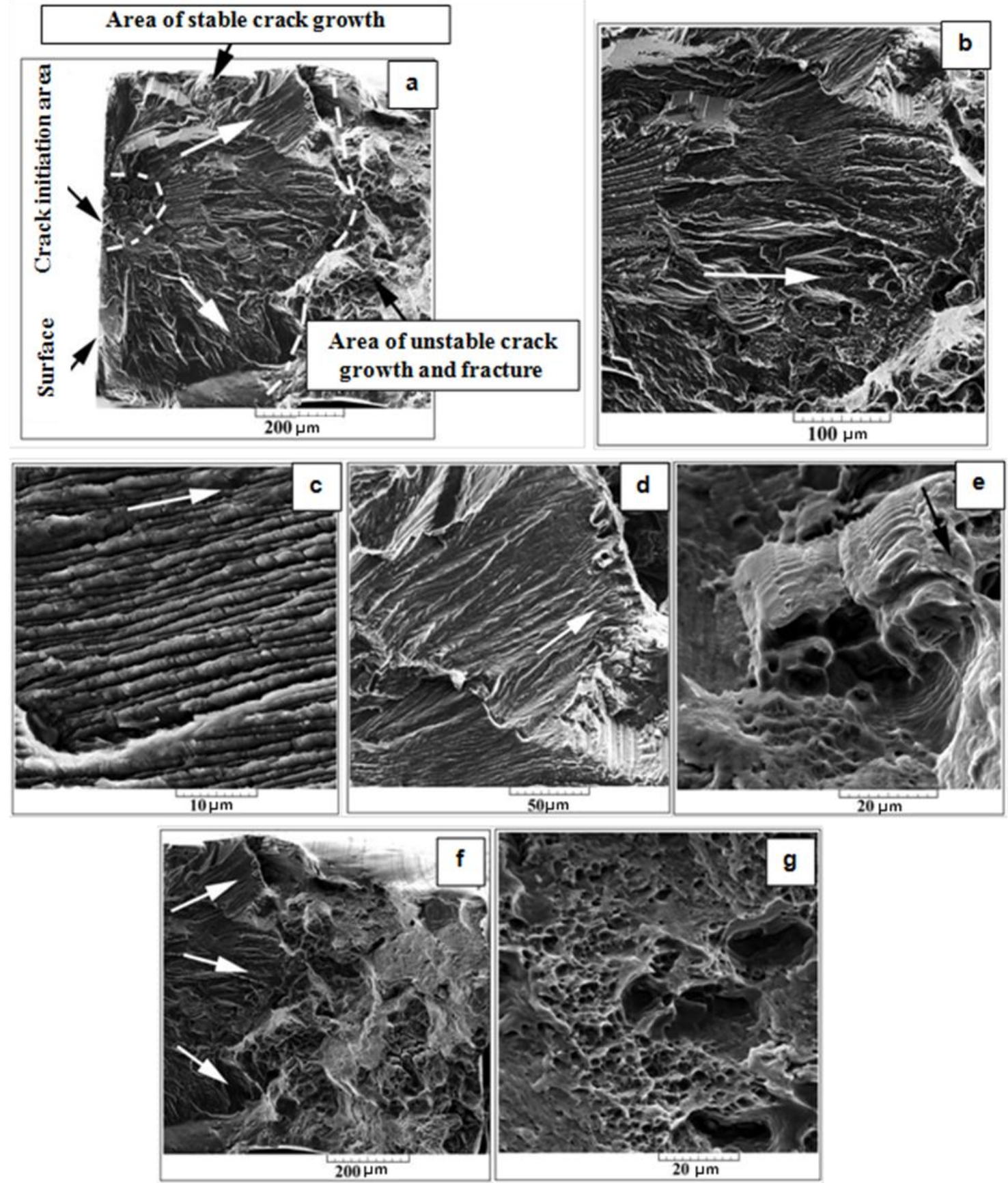

Figure 6. SEM images of the fatigue fracture surface of the CG T6 Al 6061 alloy tested under a stress amplitude of $150 \mathrm{MPa}$ to $2.2 \times 10^{5}$ cycles) (the arrows indicate the direction of fatigue crack propagation). 

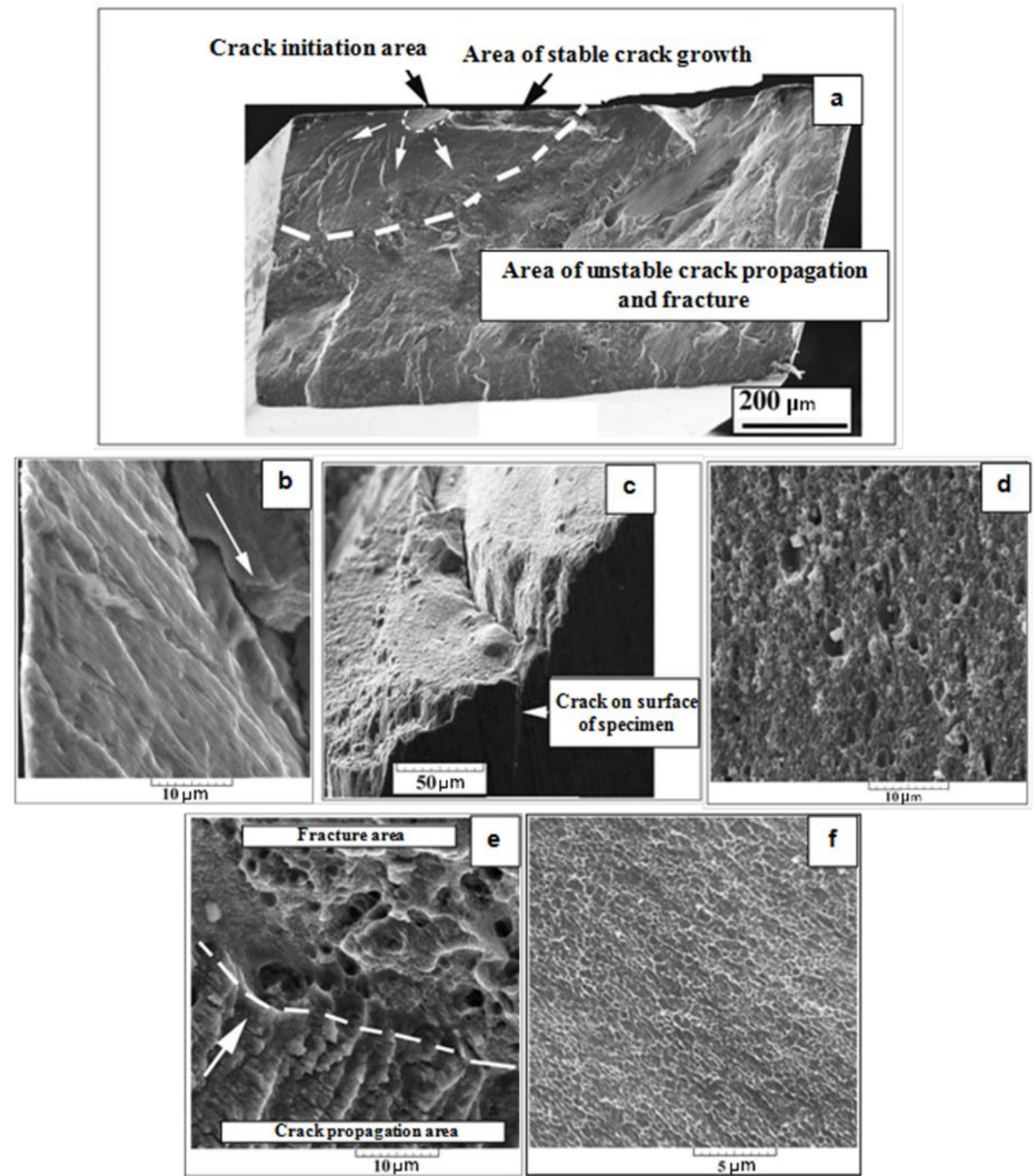

Figure 7. SEM images of the fatigue fracture surface of the UFG Al 6061 alloy: $(\mathbf{a}, \mathbf{b}, \mathbf{e}, \mathbf{f})$ tested under a stress amplitude of $225 \mathrm{MPa}$ to $4.4 \times 10^{5}$ cycles; (c,d) tested under a stress amplitude of $200 \mathrm{MPa}$ to $4.35 \times 10^{4}$ cycles (the arrows indicate the direction of fatigue crack propagation).

Similar stages of fatigue crack initiation and propagation can be also easily defined on the fatigue fracture surface of the HPT-processed alloy (Figure 7). The area of fatigue crack initiation is also located on the surface of specimens, though its size is smaller: $\sim 50 \mu \mathrm{m}$ (Figure 7a). The fracture surface relief in the areas of stable and unstable crack growth is less developed as compared to that on in the fatigue-tested CG T6 specimens. Brittle striations are observed in the area of stable crack propagation in the UFG material (Figure 7b) [36]. Unlike in the fatigue-tested CG T6 specimens, 
stable and unstable crack propagation is accompanied by the formation and growth of micro-cracks in the direction parallel to the applied load (Figure 7c). The length of these micro-cracks is $50-100 \mu \mathrm{m}$. These micro-cracks should result in energy dissipation, thus delaying the growth of the main fatigue crack [35]. The dimpled ductile fracture surface is observed in the area of unstable crack growth and the final fracture of the specimen (Figure 7d-g). However, the size of these dimples is in the range of 1-2 $\mu \mathrm{m}$, which is much lower compared to that in the CG T6 material. A significant difference in the morphology of fatigue fracture surfaces of the CG T6-treated and UFG Al 6061 alloy can be related to the grain structure of these material conditions. As is well known, during the loading phase, the crack is opened by normal stress, which activates plastic slips at the tip. At the crack tip of the CG T6 material with a grain size of $70 \mu \mathrm{m}$, dislocations are generated in the grain interior and do not necessarily reach the grain boundaries, when the material is cyclically deformed in Stage II. Conventional transgranular fatigue crack growth followed by specimen failure is observed. In the UFG material with a grain size of $170 \mathrm{~nm}$, dislocation pile-ups are definitely formed at grain boundaries near the crack tip, and intragranular slip coupled with grain boundary sliding can occur [37]. Unaccommodated grain boundary sliding might result in local microcracking or nanovoid formation at grain boundaries. Triple junction nanovoids can also appear due to unaccommodated grain boundary sliding. Both transgranular and intragranular fatigue crack growth can take place in Stage II in this case, though this cannot be clearly resolved in SEM due to the very small grain size. In Stage III, nanovoids can grow and partially relieve the constraints on a grain. Individual single crystal ligaments deform extensively and finally experience chisel-point failure. These grain boundary and triple junction voids also act as sites for nucleation of the dimples in the UFG alloy, which are significantly larger than the individual grains, and the rim of these dimples on the fracture surface $(1-2 \mu \mathrm{m})$ is typically a magnitude larger than the grain size $(170 \mathrm{~nm})$ [37].

\section{Conclusions}

The following conclusions are outlined.

1. High-pressure torsion (HPT) of the Al 6061 alloy at room temperature leads to the formation of a very homogeneous ultrafine-grained (UFG) microstructure with an average grain size of $170 \mathrm{~nm}$. The yield strength and ultimate tensile strength of the HPT processed alloy are increased as compared to the CG counterpart subjected to the conventional T6 heat treatment from $276 \mathrm{MPa}$ to $605 \mathrm{MPa}$ and from $365 \mathrm{MPa}$ to $675 \mathrm{MPa}$, correspondingly.

2. HPT processing of the Al 6061 alloy improves its endurance limit by a factor of two (from $100 \mathrm{MPa}$ after T6 treatment to $200 \mathrm{MPa}$ after HPT). This is related to the formation of a very homogeneous UFG microstructure with homogeneous resistance to fatigue crack initiation in the HCF regime. In the LCF regime, the UFG alloy shows somewhat lower fatigue resistance due to its lower strain hardening ability.

3. Classical stages of fatigue crack initiation and propagation are clearly observed on the fatigue fracture surfaces of the CG T6-treated alloy and UFG alloy. Ductile striations are observed in the stage of stable crack propagation in the CG T6-treated alloy, whereas brittle striations seem to dominate on the fatigue fracture surface of the UFG alloy. The dimpled fracture surface is 
observed at the final stage of crack propagation in both material conditions, with dimples having a smaller size in the UFG alloy.

\section{Acknowledgments}

The work has been done under the financial support of the Russian Federal Ministry for Education and Science. R.Z. Valiev and M. Yu. Murashkin gratefully acknowledge the support through Grant No. 14.B25.31.0017, and I. Ovidko acknowledges the support through Programme "5-100-2020". I. Sabirov acknowledges gratefully the Spanish Ministry of Economy and Competitiveness for financial support through the Ramon y Cajal Fellowship.

\section{Author Contributions}

Maxim Murashkin formulated the idea of this work, processed the samples, conceived of the workflow and created the initial draft. Ilchat Sabirov carried out mechanical tensile tests and performed microstructural characterization of the processed material. Dmitriy Prosvirnin performed fatigue testing. Vladimir Terentiev performed the SEM studies of the fatigue fracture surfaces. Ilya Ovidko, Ruslan Valiev and Sergey Dobatkin contributed with the overall development of the main concepts presented in this paper. All authors discussed the experimental results, participated in manuscript preparation and approved the final manuscript.

\section{Conflicts of Interest}

The authors declare no conflict of interest.

\section{References}

1. Valiev, R.Z.; Zhilyaev, A.P.; Langdon, T.G. Bulk Nanostructured Materials: Fundamentals and Applications. John Wiley \& Sons: Hoboken, NJ, USA, 2014; p. 456.

2. Sabirov, I.; Murashkin, M.Y.; Valiev, R.Z. Nanostructured aluminium alloys produced by severe plastic deformation: New horizons in development. Mater. Sci. Eng. A 2013, 560, 1-24.

3. Markushev, M.V.; Murashkin, M.Y. Mechanical properties of submicrocrystalline Al alloys processed by equal-channel angular pressing. Phys. Met. Metall. 2000, 90, 506-515.

4. Roven, H.J.; Nesboe, H.; Werenskiold, J.C.; Seibert, T. Mechanical properties of aluminum alloys processed by SPD: Comparison of different alloy systems and possible product areas. Mater. Sci. Eng. A 2005, 410-411, 426-429.

5. Lyakishev, N.P.; Alymov, M.I.; Dobatkin, S.V. Structural bulk nanomaterials. Russ. Metall. 2003, 3, 191-202.

6. Dobatkin, S.V.; Zakharov, V.V.; Vinogradov, A.Y.; Kitagava, N.; Krasilnikov, N.A.; Rostova, T.D.; Bastrash, E.N. Nanocrystalline structure in Al-Mg-Sc alloys by severe plastic deformation. Russ. Metall. 2006, 6, 533-540.

7. Zhao, Y.; Liao, X.; Cheng, S.; Ma, E.; Zhu, Y. Simultaneously increasing the ductility and strength of nanostructured alloys. Adv. Mater. 2006, 18, 2280-2283. 
8. Horita, Z.; Ohashi, K.; Fujita, T.; Kaneko, K.; Langdon, T.G. Achieving high strength and high ductility in precipitation-hardened alloys. Adv. Mater. 2005, 17, 1599-1603.

9. Markushev, M.V.; Bampton, C.C.; Murashkin, M.Y.; Hardwick, D.A. Structure and properties of ultra-fine grained Al alloys produced by severe plastic deformation. Mater. Sci. Eng. A. 1997, 234-236, 927-931.

10. Murashkin, M.; Sabirov, I.; Kazykhanov, V.; Bobruk, E.; Dubravina, A.; Valiev, R.Z. Enhanced mechanical properties and electrical conductivity in ultra-fine grained $\mathrm{Al}$ alloy processed via ECAP-PC. J. Mater. Sci. 2013, 48, 4501-4509.

11. Valiev, R.Z.; Murashkin, M.Y.; Sabirov, I. A nanostructural design to produce high-strength Al alloys with enhanced electrical conductivity. Scr. Mater. 2014, 76, 13-16.

12. Vinogradov, A.Y.; Khasimoto, S. Fatigue in ultrafine-grained materials processed by equal-channel angular pressing. Russ. Metall. 2004, 1, 42-51.

13. Estrin, Y.; Vinogradov, A. Fatigue behaviour of light alloys with ultrafine grain structure produced by severe plastic deformation: An overview. Int. J. Fatigue 2010, 32, 898-907.

14. Estrin, Y.; Vinogradov, A. Extreme grain refinement by severe plastic deformation: A wealth of challenging science. Acta Mater. 2013, 61, 782-817.

15. Höppel, W.; Kautz, M.; Murashkin, M.Y.; Xu, C.; Langdon, T.G.; Valiev, R.Z.; Mughrabi, H. An overview: Fatigue Behavior of Ultrafine-Grained Metals and Alloys. Int. J. Fatigue 2006, 28, 1001-1010.

16. Höpel, H.W.; Göken, M. Fatigue Behavior in Nanostructured Metals. In Nanostructured Metals and Alloys: Processing, Microstructure, Mechanical Properties and Applications; Whang, S.H., Ed.; Woodhead Publishing Limited: Suite, PA, USA, 2011; pp. 507-541.

17. Mughrabi, H.; Höppel, H.W.; Kautz, M. Fatigue and microstructure of ultra-fine grained metals produced by severe plastic deformation. Scr. Mater. 2004, 51, 807-812.

18. Malekjani, S.; Hodgson, P.D.; Cizek, P.; Sabirov, I.; Hilditch, T.B. Cyclic deformation response of UFG $2024 \mathrm{Al}$ alloy. Int. J. Fatigue 2011, 33, 700-709.

19. Canadinc, D.; Maier, H.J.; Gabor, P.; May, J. On the cyclic deformation response of ultrafine-grained Al-Mg alloys at elevated temperatures. Mater. Sci. Eng. A 2008, 496, 114-120.

20. Vinogradov, A.; Washikita, A.; Kitagawa, K.; Kopylov, V.I. Fatigue life of fine-grain Al-Mg-Sc alloys produced by equal-channel angular pressing. Mater. Sci. Eng. A 2003, 349, 318-326.

21. Chung, C.S.; Kim, J.K.; Kim, H.K.; Kim, W.J. Improvement of high-cycle fatigue life in a 6061 Al alloy produced by equal channel angular pressing. Mater. Sci. Eng. A 2002, 337, 39-44.

22. Lapovok, R.; Loader, C.; Dalla Torre, F.H.; Semiatin, S.L. Microstructure evolution and fatigue behavior of 2124 aluminum processed by ECAE with back pressure. Mater. Sci. Eng. A 2006, 425, 36-46.

23. Malekjani, S.; Hodgson, P.D.; Cizek, P.; Hilditch, T.B. Cyclic deformation response of ultra-fine pure Al. Acta Mater. 2011, 59, 5358-5367.

24. Valiev, R.Z.; Enikeev, N.A.; Murashkin, M.Y.; Kazykhanov, V.U.; Sauvage, X. On the origin of the extremely high strength of ultra-fine grained Al alloys. Scr. Mater. 2010, 63, 949-952.

25. Liddicoat, P.V.; Liao, X.Z.; Zhao, Y.; Zhu, Y.; Murashkin, M.Y.; Lavernia, E.J.; Valiev, R.Z.; Ringer, S.P. Nanostructural hierarchy increases the strength of aluminium alloys. Nat. Comm. 2010, $1,63-70$. 
26. Ruffing, C.; Ivanisenko, Y.; Kerscher, E. Fatigue behavior of ultrafine grained medium Carbon steel processed by severe plastic deformation. IOP Conf. Series: Mater. Sci. Eng. 2014, 63, 012163.

27. Polmear, I.J. Light Alloys. In From Traditional Alloys to Nanocrystals; Butterworth-Heinemann: Oxford, UK, 2006; p. 417.

28. Mondolfo, L.F. Aluminum Alloys: Structure and Properties; Butterworth: Oxford, UK, 1976; p. 971.

29. Murayama, M.; Hono, K. Pre-precipitate clusters and precipitation processes in Al-Mg-Si alloys. Acta Mater. 1999, 47, 1537-1548.

30. Nurislamova, G.; Sauvage, X.; Murashkin, M.; Islamgaliev, R.; Valiev, R. Nanostructure and related mechanical properties of an Al-Mg-Si alloy processed by severe plastic deformation. Phil. Mag. Lett. 2008, 88, 459-466.

31. Moreno-Valle, E.C.; Sabirov, I.; Perez-Prado, M.T.; Murashkin, M.Y.; Bobruk, E.V.; Valiev, R.Z. Effect of the grain refinement via severe plastic deformation on strength properties and deformation behavior of an $\mathrm{Al} 6061$ alloy at room and cryogenic temperatures. Mater. Lett. 2011, 65, 2917-2919.

32. Sha, G.; Tugcu, K.; Liao, X.Z.; Trimby, P.W.; Murashkin, M.Y.; Valiev, R.Z.; Ringer, S.P. Strength, grain refinement and solute nanostructures of an Al-Mg-Si alloy (AA6060) processed by high-pressure torsion. Acta Mater. 2014, 63, 169-179.

33. Murashkin, M.Y.; Markushev, M.V.; Ivanisenko, Y.V.; Valiev, R.Z. Strength of commercial aluminum alloys after equal channel angular pressing and post-ECAP processing. Solid State Phen. 2006, 114, 91-96.

34. Hatch, J.E. Aluminium: Properties and Physical Metallurgy; ASM International: Materials Park, OH, USA, 1984; p. 636.

35. Suresh, S. Fatigue of Materials; Cambridge University Press: Cambridge, UK, 1998; p. 679.

36. Milella, P.P. Fatigue and Corrosion in Metals; Springer: Berlin, Germany, 2013; p. 763.

37. Dalla Torre, F.; van Swygenhoven, H.; Victoria, M. Nanocrystalline electrodeposited Ni: Microstructure and tensile properties. Acta Mater. 2002, 50, 3957-3970.

(C) 2015 by the authors; licensee MDPI, Basel, Switzerland. This article is an open access article distributed under the terms and conditions of the Creative Commons Attribution license (http://creativecommons.org/licenses/by/4.0/). 